\title{
Co-seismic geomagnetic fluctuations and atmospheric disturbances during the 2018 M 6.2 Hualien Earthquake
}

\author{
Chun-Rong Chen ${ }^{1}$, Jann-Yenq Liu ${ }^{1,2,3, *}$, Chieh-Hung Chen ${ }^{4,5}$, Tsung-Yu Wu ${ }^{1}$, Horng-Yuan Yen ${ }^{6}$, \\ Strong Wen ${ }^{7}$, Bor-Shouh Huang ${ }^{8}$, Cheng-Horng Lin $^{8}$, Che-Min Lin ${ }^{9}$, and Hung-Hao Hsieh ${ }^{9}$ \\ ${ }^{1}$ Graduate Institute of Space Science, National Central University, Taoyuan City, Taiwan \\ ${ }^{2}$ Center for Astronautical Physics and Engineering, National Central University, Taoyuan City, Taiwan \\ ${ }^{3}$ Center for Space and Remote Sensing Research, National Central University, Taoyuan City, Taiwan \\ ${ }^{4}$ Institute of Geophysics and Geomatics, China University of Geosciences, Wuhan, China \\ ${ }^{5}$ State Key Laboratory of Geological Processes and Mineral Resources, Institute of Geophysics and Geomatics, China University \\ of Geosciences, Wuhan, China \\ ${ }^{6}$ Department of Earth Sciences, National Central University, Taoyuan City, Taiwan \\ ${ }^{7}$ Department of Earth and Environmental Sciences, National Chung Cheng University, Chayi County, Taiwan \\ ${ }^{8}$ Institute of Earth Sciences, Academia Sinica, Taipei City, Taiwan \\ ${ }^{9}$ National Center for Research on Earthquake Engineering, Taipei City, Taiwan
}

\section{Article history:}

Received 2 January 2019

Revised 11 March 2019

Accepted 11 March 2019

Keywords:

Geomagnetic, QuakeFinder, Infrasound, Micro-Barometer, Tiltmeter

Citation:

Chen, C.-R., J.-Y. Liu, C.-H. Chen, T.-Y. Wu, H.-Y. Yen, S. Wen, B.-S. Huang, C.-H. Lin, C.-M. Lin, and H.H. Hsieh, 2019: Co-seismic geomagnetic fluctuations and atmospheric disturbances during the 2018 M 6.2 Hualien Earthquake. Terr. Atmos. Ocean. Sci., 30,449-465, doi: 10.3319/ TAO.2019.03.11.01

\begin{abstract}
The strong ground motion of 6 February 2018 M 6.2 Hualien Earthquake triggered a series of co-seismic geomagnetic fluctuations and seismo-traveling atmospheric disturbances (STADs) signatures in infrasonic waves and micro-pressures upon the seismic wave arrival. Networks of 9 QuakeFinder systems, 3 infrasound systems, 2 tiltmeters, 2 micro-barometers, and 11 co-located seismometers are used in this study. Each QuakeFinder system consists of a 3-axes induction magnetometer, an air conductivity sensor, a geophone, and temperature/relative humidity sensors. Co-seismic signatures clearly appear in the induction magnetometers, infrasound systems, and micro-barometers data. The magnetometers register both high- and lowfrequency pulsations. Geomagnetic fluctuations occur upon the seismic wave arrival but last a longer duration, while the STADs lag their co-located seismic waves by about $15-45 \mathrm{~s}$. The long-lasting fluctuations recorded by both induction and fluxgate magnetometers suggest that the ground/underground water motion play an important role, which is further conformed by low-frequency fluctuations in the tiltmeter data. In general, the amplitude of geomagnetic fluctuations decays as away from the epicenter. However, unusual large co-seismic geomagnetic fluctuations are detected over areas of the abnormal seismic intensity level and/or the magnetic underground structure with anomalously high susceptibilities.
\end{abstract}

\section{INTRODUCTION}

The large ground motion of earthquake could trigger acoustic and/or gravity waves, termed seismo-traveling atmospheric disturbances (STADs), in the neutral atmosphere near the Earth's surface. Seismometers (or geophones) recorded the seismic waves which monitoring the Earth's ground motion (Shearer 1999), and infrasound (or microBarometers) systems measure atmospheric pressure changes induced by the Earth's surface motion and/or seismic waves,

\footnotetext{
* Corresponding author

E-mail: tigerjyliu@gmail.com
}

especially Rayleigh waves which transit in the near surface (Mutschlecner and Whitaker 2005; Liu et al. 2006, 2010, 2016a, 2017). In some cases, STADs could further travel into the ionosphere and interact with the ionized gas resulting in seismo-traveling ionospheric disturbances (STIDs) [see papers listed in Davies (1990)]. Meanwhile, scientists reported that co-seismic geomagnetic pulsations can result from instrument oscillations due to seismic waves ( $\mathrm{Li}$ et al. 2018) and regional geomagnetic field fluctuations induced by STIDs (Iyemori et al. 1996, 2005; Honkura et al. 2002; Azeez et al. 2009; Widarto et al. 2009; Hao et al. 2013; Gao et al. 2014; Yen et al. 2015; Liu et al. 2016a). Due to the 
low sampling rate, co-seismic fluctuations in the geomagnetic field were hard to distinguish from the effect of magnetometer sensor oscillation (Breiner 1964; Eleman 1965), and therefore, high resolution (e.g., $1 \mathrm{~Hz}$ ) observation are necessary for such researches (Iyemori et al. 1996). Liu et al. (1993) shows that the amplitude of differential quantities (i.e., derivative quantities) is proportional to its oscillation angular frequency. Thus, an induction magnetometer recording derivative quantities of the time rate change of the magnetic field has a better performance than a total field or a fluxgate one (i.e., integral quantity) in detecting highfrequency/small pulsations. By contrast, a total field or a fluxgate magnetometer is suitable to observer long-period magnetic variations (such as diurnal variations, magnetic storms, sea effects, and manmade noises, etc.).

To enhance the iSTEP (integrated Search for Taiwan Earthquake Precursor) project established in 2003 for integrating study and test earthquake precursors (Liu et al. 2016b,c), networks of 5 infrasound systems and 3 micro-barometers with a sampling rate of $1 \mathrm{~Hz}, 15$ QuakeFinder systems with a sampling rate of $50 \mathrm{~Hz}$, and 3 tiltmeter systems with a sampling rate of $1 \mathrm{~Hz}$ have been setup and operated in Taiwan. The infrasound and micro-barometer systems are used to record the atmospheric VLF (very low frequency, in the period range $0.5-200 \mathrm{~s}$ ) sounds. QuakeFinder system major consists of 8 sensors, an induction magnetometer with 3-component, positive/negative air conductivity sensors, a geophone, and 2 environmental sensors which measure the relative magnetic pulsations, positive/negative ion concentrations, the surface oscillation, and ambient temperature/ humidity, respectively. Note that the induction magnetometer in QuakeFinder with high resolution of $50 \mathrm{~Hz}$ is very sensitive and suitable for detecting co-seismic magnetic signatures (Liu et al. 2017). On the other hand, 3 fluxgate magnetometers from Institute of Earth Science, Academia Sinica (IES) and 10 proton magnetometers from Central Weather Bureau (CWB) of Taiwan are also used to further cross compare with the QuakeFinder induction magnetometers. Moreover, the high sensitivity tiltmeters with resolution in microradian are employed to improve the detectability on the faint oscillation in Earth's surface.

An earthquake with a moment magnitude of 6.2 struck the Milun region, Hualien at 23:50 local time (15:50 UTC) on 6 February 2018 . The epicenter is located at $24.10^{\circ} \mathrm{N}$, $121.73^{\circ} \mathrm{E}$ and in a relatively shallow depth of around $6.3 \mathrm{~km}$. The comparatively shallow depth caused a maximum seismic intensity of 7 in the Hualien city, and resulted in several buildings crashed, about 300 people injured and 17 deaths. The earthquake is one of the deadliest quakes in the recent two decades. In this paper, 14 seismometers with a sampling rate of $100 \mathrm{~Hz}$ of the short period observation network published CWB (http://gdms.cwb.gov.tw/index. php) and National Center for Research on Earthquake Engineering (NCREE) nearby the iSTEP stations are used as the reference of seismic waves. Concurrent/co-located measurements of the seismometer, QuakeFinder systems, infrasound systems (micro-barometers), and tiltmeters are employed to record seismic waves, geomagnetic field, induced disturbances in the neutral atmosphere near the Earth's surface, and surface oscillation, respectively during the M 6.2 Hualien Earthquake.

\section{EXPERIMENT SETUP AND OBSERVATION}

During the 2018 M 6.2 Hualien Milun Earthquake event, 9 QuakeFinder systems together with 3 infrasound systems, 2 tiltmeters, and 2 micro-barometers were in well operation. The sampling rate of the QuakeFinder system is 50 sps (sample per second, Hz). The 3-componenet induction magnetometer probes magnetic pulsation in $\mathrm{nT} \mathrm{s}^{-1}$ with the sensitivity at $1 \mathrm{~Hz}: 0.1 \mathrm{~V} \mathrm{nT}^{-1}$, and the noise level: $0.1 \mathrm{pT}$ per root $\mathrm{Hz}$ at $1 \mathrm{~Hz}$ and $0.02 \mathrm{pT}$ per root $\mathrm{Hz}$ at $10 \mathrm{~Hz}$. The geophone data with the natural frequency $4.5 \pm 0.5 \mathrm{~Hz}$ (max tilt angle $25^{\circ}$ ) and the sensitivity of $27.0 \mathrm{~V} \mathrm{~m}^{-1} \mathrm{~s}^{-1} \pm 10 \%$ which measuring the northward direction of the ground motion velocity in $\mathrm{cm} \mathrm{s}^{-1}$. The high sampling rate, high sensitivity, and low noise are suitable and useful to detect related co-seismic signatures. For observing long-period co-seismic signatures, 3 infrasound systems with $1 \mathrm{~Hz}$ sampling rate and a sensitivity of $0.01 \mathrm{~Pa}$ in the frequency range $0.5-200 \mathrm{~s}$ and a dynamic range of $80 \mathrm{~dB}$ (Xia et al. 2011); 2 tiltmeters having $\mathrm{X}$ - and $\mathrm{Y}$-component with $1 \mathrm{~Hz}$ sampling rate and response in \pm 300 microradians $\left(5.7 \times 10^{-5}\right.$ degrees $)$; and 2 micro-barometers with $1 \mathrm{~Hz}$ sampling rate and sensitivity in $0.01 \mathrm{~Pa}$ are employed. Meanwhile, 10 seismometers from CWB and 4 seismometers from NCREE with the sampling rate of $100 \mathrm{~Hz}$ were chosen as the reference for cross comparing with observations of co-located and/or nearby the iSTEP instruments. For further understanding on co-seismic signatures, 3 fluxgate magnetometers with the sampling rate of $10 \mathrm{~Hz}$ and the sensitivity of $0.01 \mathrm{nT}$ from IES recording magnetic strength and 10 proton magnetometers with the sampling rate of $1 \mathrm{~Hz}$ and the sensitivity of $0.01 \mathrm{nT}$ from CWB measuring the absolute total field are also used.

Figure 1 displays locations of the Hualien Earthquake; 9 co-located QF (QuakeFinder) sites consisting of the 9 QuakeFinder system, 9 seismometers, and 3 infrasounds (denoted by black dashed circles); 2 co-located TB (tiltmeters/ micro-barometers) sites consisting of the 2 tiltmeters/microbarometers and 2 seismometers (denoted by green dashed circles); as well as the 3 fluxgate magnetometers, and 10 proton total magnetometers. The dashed circle with a $20-\mathrm{km}$ radius denotes co-located sensors/instruments in the region, where seismic waves yield a limited time lag of about $15 \mathrm{~s}$ (Kuo-Chen et al. 2012; Huang et al. 2014). The background map of the geomagnetic anomaly in Fig. 1 is adapted from Yen et al. (2009), which provides the information about underground magnetic structures. After the earthquake occurs, 
the seismic waves propagate through whole island-wide and triggered co-seismic fluctuations have been recorded by the sensors/instruments. Table 1 lists the station name, instrument type, location, and distance to the epicenter.

Figure 2 depicts the magnetic induction in northward $\left(\dot{\mathrm{B}_{\mathrm{N}}}\right)$, eastward $\left(\dot{\mathrm{B}_{\mathrm{E}}}\right)$ and upward $\left(\dot{\mathrm{B}}_{\mathrm{Z}}\right)$, geophone $(\mathrm{V})$, seismograms in northward $\left(\mathrm{V}_{\mathrm{N}}\right)$, eastward $\left(\mathrm{V}_{\mathrm{E}}\right)$, and upward $\left(\mathrm{V}_{\mathrm{Z}}\right)$, and infrasonic wave $(\mathrm{P})$ (in the bottom of Panels $\mathrm{A}$, D, and G) at the 9 QF sites. Similar to Liu et al. (2017), no obvious co-seismic signatures in the air conductivity, temperature, and relative humidity were detected. The colocated QuakeFinder systems and seismometers show that co-seismic geomagnetic pulsations superposed up some long-period variations at the $9 \mathrm{QF}$ sites, except the farthest 2 sites of SW and KD. Packet fluctuations in the geophone are similar to those in the co-site seismometer, especially in the $\mathrm{V}_{\mathrm{N}}$ and $\mathrm{V}_{\mathrm{E}}$ component. The geophone is horizontally placed in the northward direction and therefore, is more sensitive to the $\mathrm{S}$-wave. Small signal/noise ratios in $\dot{\mathrm{B}_{\mathrm{N}}}, \dot{\mathrm{B}_{\mathrm{E}}}$, and $\dot{\mathrm{B}_{\mathrm{Z}}}$ at WT as well as in $\dot{\mathrm{B}}_{\mathrm{Z}}$ at $\mathrm{SW}$ and $\mathrm{KD}$ might result from no obvious co-seismic geomagnetic signatures at the farthest 2 sites. On the hand, co-seismic signatures in the geophones are generally similar to the co-located seismic waves, except a sinusoidal trend superposing with seismic waves at CC. Panels A, D, and G display that co-seismic fluctuations recorded by the 3 infrasound systems. Due to very close to the epicenter, there is almost no time lag between co-seismic infrasonic waves and seismic waves at DHU, while the time lags become greater for the other two infrasounds away from the epicenter. Nevertheless, in comparing the seismic waves, the infrasonic waves generally are more fluctuated.

Figure 3 illustrates co-seismic tiltings in the tiltmeters, pressure changes in the micro-barometers, and the associate seismic waves at the 2 TB sites. Due to data gaps of the seismometer at LUG, a nearby seismometer at WSL is used. Co-seismic tiltings yield a much longer duration than the co-located seismic waves. At NAH, due to the tiltmeter being crept, the co-seismic tilting yields some overstepping. While the micro-barometer data at LUG are too noisy to observe any co-seismic signature, those at NAH show a short prominent package of co-seismic fluctuations soon after the seismic wave arrival.

Scientists (Yeh et al. 1981; Chen et al. 2011, 2013, 2014; Han et al. 2014; Liu et al. 2017) show that spectrum analyses provide a better understanding on studied signals. Figure 4 illustrates power spectra of the high sampling data of QuakeFinder systems and seismometers, where we can see that the magnetic pulsations are monotonically inversely proportional to the frequency, and those of co-seismic geophone fluctuations and the seismic waves yield peaks around

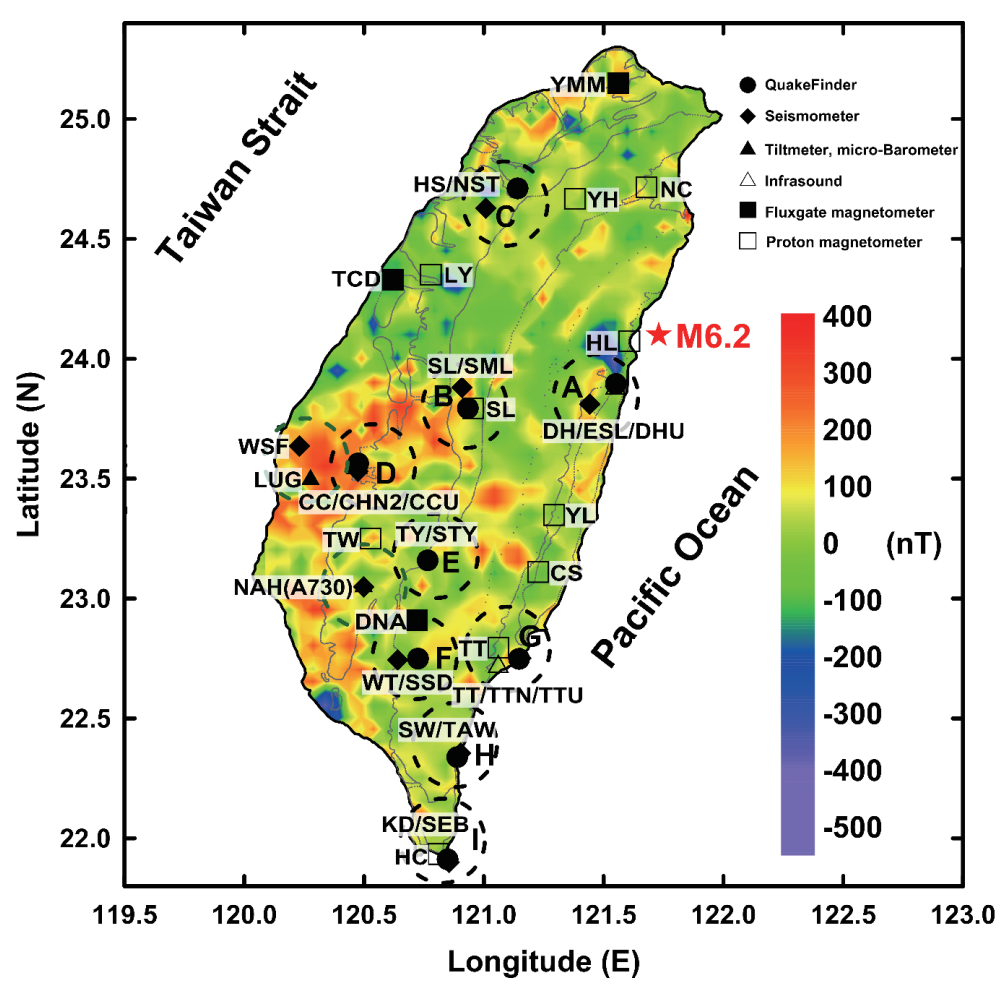

Fig. 1. Geomagnetic anomaly map and the locations of the Hualien Earthquake and measurement stations. The geomagnetic anomaly using the same data with Yen et al. (2009) and doing low-pass filtering process after a careful data selection to eliminate spikes. The red star is the 2018 M 6.2 Hualien Earthquake; the solid circle denoted the QuakeFinder systems; the solid diamonds mark the co-location seismometers; the solid triangles shows the tiltmeters and micro-barometers; the open triangles are infrasound systems; the solid rectangles are fluxgate magnetometers. Note that, dashed circle with 20-km radius indicate the instruments set which are comparable due to similar locations. 
Table 1. Station Locations and Their Distances to the Epicenter.

\begin{tabular}{|c|c|c|c|c|}
\hline Station & Instrument Type & Latitude $\left({ }^{\circ} \mathbf{N}\right)$ & Longitude $\left({ }^{\circ} \mathbf{E}\right)$ & Distance to epicenter $(\mathrm{km})$ \\
\hline DH & QuakeFinder & 23.896 & 121.551 & 32.61 \\
\hline ESL & Seismometer & 23.812 & 121.442 & 43.41 \\
\hline DHU & Infrasound & 23.890 & 121.550 & 29.66 \\
\hline HS & QuakeFinder & 24.711 & 121.140 & 79.15 \\
\hline NST & Seismometer & 24.629 & 121.009 & 93.84 \\
\hline SL & QuakeFinder & 23.795 & 120.933 & 84.41 \\
\hline SML & Seismometer & 23.881 & 120.908 & 82.33 \\
\hline $\mathrm{CC}$ & QuakeFinder & 23.565 & 120.475 & 137.59 \\
\hline CHN2 & Seismometer & 23.532 & 120.474 & 139.51 \\
\hline $\mathrm{CCU}$ & Infrasound & 23.560 & 120.470 & 141.52 \\
\hline TY & QuakeFinder & 23.160 & 120.765 & 144.48 \\
\hline STY & Seismometer & 23.161 & 120.766 & 144.43 \\
\hline WT & QuakeFinder & 22.751 & 120.725 & 184.36 \\
\hline SSD & Seismometer & 22.744 & 120.640 & 189.58 \\
\hline $\mathrm{TT}$ & QuakeFinder & 22.749 & 121.147 & 166.59 \\
\hline TTN & Seismometer & 22.752 & 121.155 & 166.03 \\
\hline TTU & Infrasound & 22.730 & 121.060 & 166.97 \\
\hline SW & QuakeFinder & 22.340 & 120.889 & 218.40 \\
\hline TAW & Seismometer & 22.356 & 120.904 & 216.17 \\
\hline $\mathrm{KD}$ & QuakeFinder & 21.913 & 120.849 & 264.48 \\
\hline SEB & Seismometer & 21.901 & 120.855 & 265.60 \\
\hline LUG & Tiltmeter/micro-Barometer & 23.497 & 120.276 & 158.98 \\
\hline WSF & Seismometer & 23.636 & 120.230 & 161.01 \\
\hline $\mathrm{NAH}$ & Tiltmeter/micro-Barometer & 23.049 & 120.498 & 171.67 \\
\hline A730 & Seismometer & 23.049 & 120.498 & 171.67 \\
\hline TCD & Fluxgate magnetometer & 24.330 & 120.620 & 106.15 \\
\hline YMM & Fluxgate magnetometer & 25.150 & 121.560 & 108.93 \\
\hline DNA & Fluxgate magnetometer & 22.910 & 120.720 & 169.69 \\
\hline $\mathrm{HL}$ & Proton magnetometer & 24.074 & 121.608 & 12.73 \\
\hline $\mathrm{NC}$ & Proton magnetometer & 24.717 & 121.679 & 68.75 \\
\hline YH & Proton magnetometer & 24.668 & 121.379 & 72.46 \\
\hline SL & Proton magnetometer & 23.794 & 120.956 & 85.71 \\
\hline YL & Proton magnetometer & 23.349 & 121.294 & 94.54 \\
\hline LY & Proton magnetometer & 24.352 & 120.779 & 100.43 \\
\hline CS & Proton magnetometer & 23.112 & 121.226 & 121.30 \\
\hline $\mathrm{TW}$ & Proton magnetometer & 23022 & 120.527 & 154.57 \\
\hline TT & Proton magnetometer & 22.796 & 121.061 & 160.21 \\
\hline $\mathrm{HC}$ & Proton magnetometer & 21.936 & 120.810 & 258.41 \\
\hline
\end{tabular}



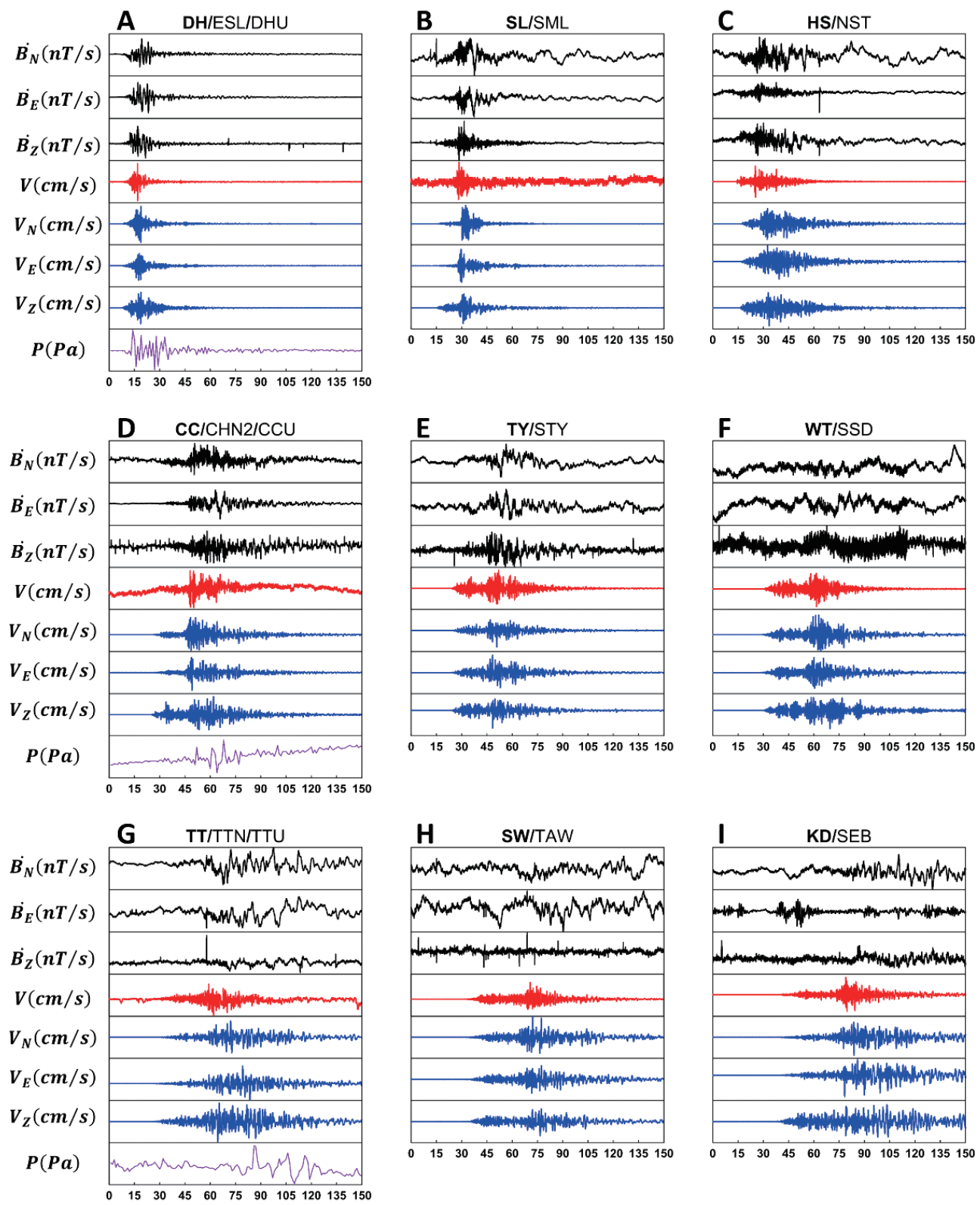

\section{Time after the earthquake (sec)}

Fig. 2. Raw data recorded by the magnetometers, seismometers, and infrasound systems. For top to down, magnetic pulsations in nT in the N (northward, $\mathrm{B}_{\mathrm{N}}$ ), $\mathrm{E}$ (eastward, $\mathrm{B}_{\mathrm{E}}$ ), and $\mathrm{Z}$ (upward, $\dot{\mathrm{B}}_{\mathrm{Z}}$ ) directions, the geophone oscillations in $\mathrm{cm} \mathrm{s}^{-1}$, the seismometers in $\mathrm{cm} \mathrm{s}^{-1}$ in northward $\left(\mathrm{V}_{\mathrm{N}}\right.$ ), eastward $\left(\mathrm{V}_{\mathrm{E}}\right)$, and upward $\left(\mathrm{V}_{\mathrm{Z}}\right)$, and the infrasonic waves in $\mathrm{Pa}$, respectively. The vertical axis range is in an arbitrary scale. 
(a)

LUG (159 km) tiltmeter / micro-barometer \& WSF (166 km) seismometer

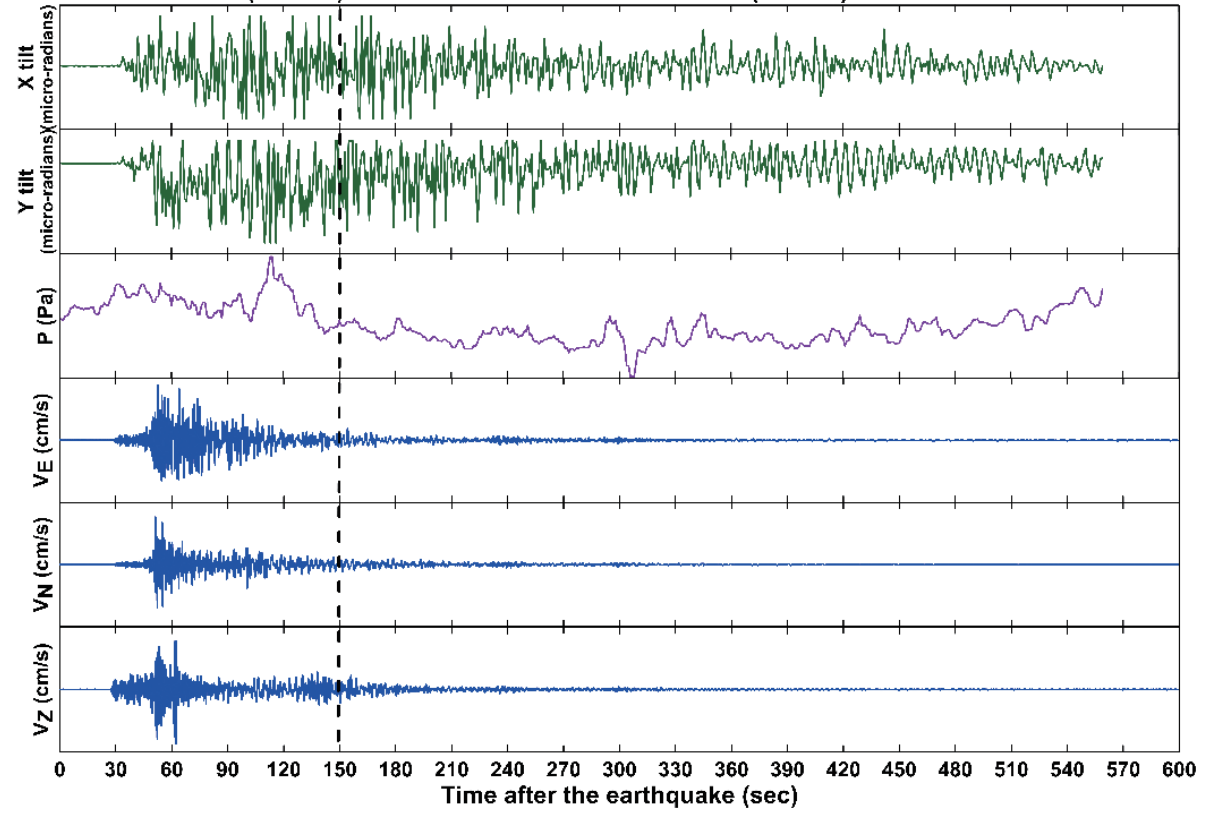

(b)

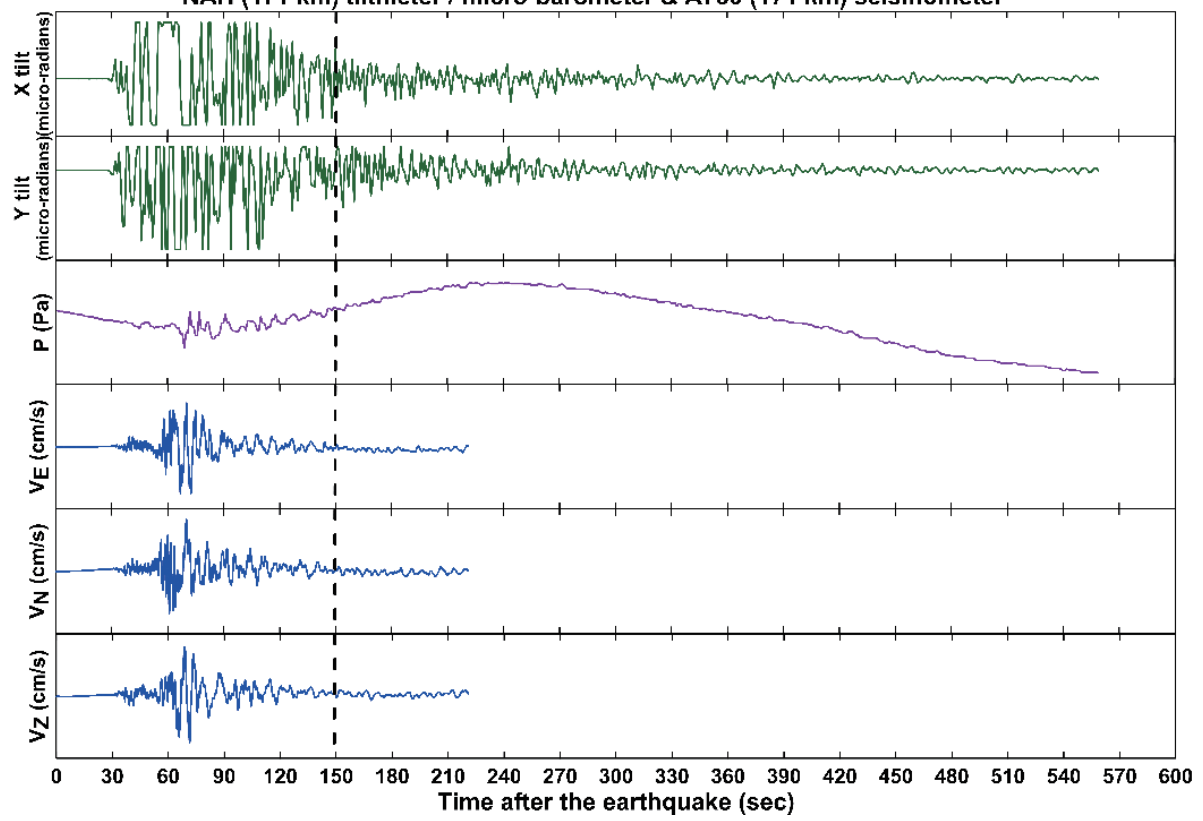

Fig. 3. Raw data recorded by the tiltmeters, micro-barometers, and seismometers. (a) Raw data in LUG station, for top to down, X-direction tilting angle in micro-radians, Y-direction tilting angle in micro-radians, micro-barometer in Pa, and seismometers at WSL station in $\mathrm{cm} \mathrm{s}^{-1}$ in northward $\left(\mathrm{V}_{\mathrm{N}}\right)$, eastward $\left(\mathrm{V}_{\mathrm{E}}\right)$, and upward $\left(\mathrm{V}_{\mathrm{Z}}\right)$. (b) Raw data in NAH station with same figure panels in block (a). Note that the dash line indicates the started point of tiltmeters testing data for spectrum analysis at NAH. The vertical axis range is in an arbitrary scale. 


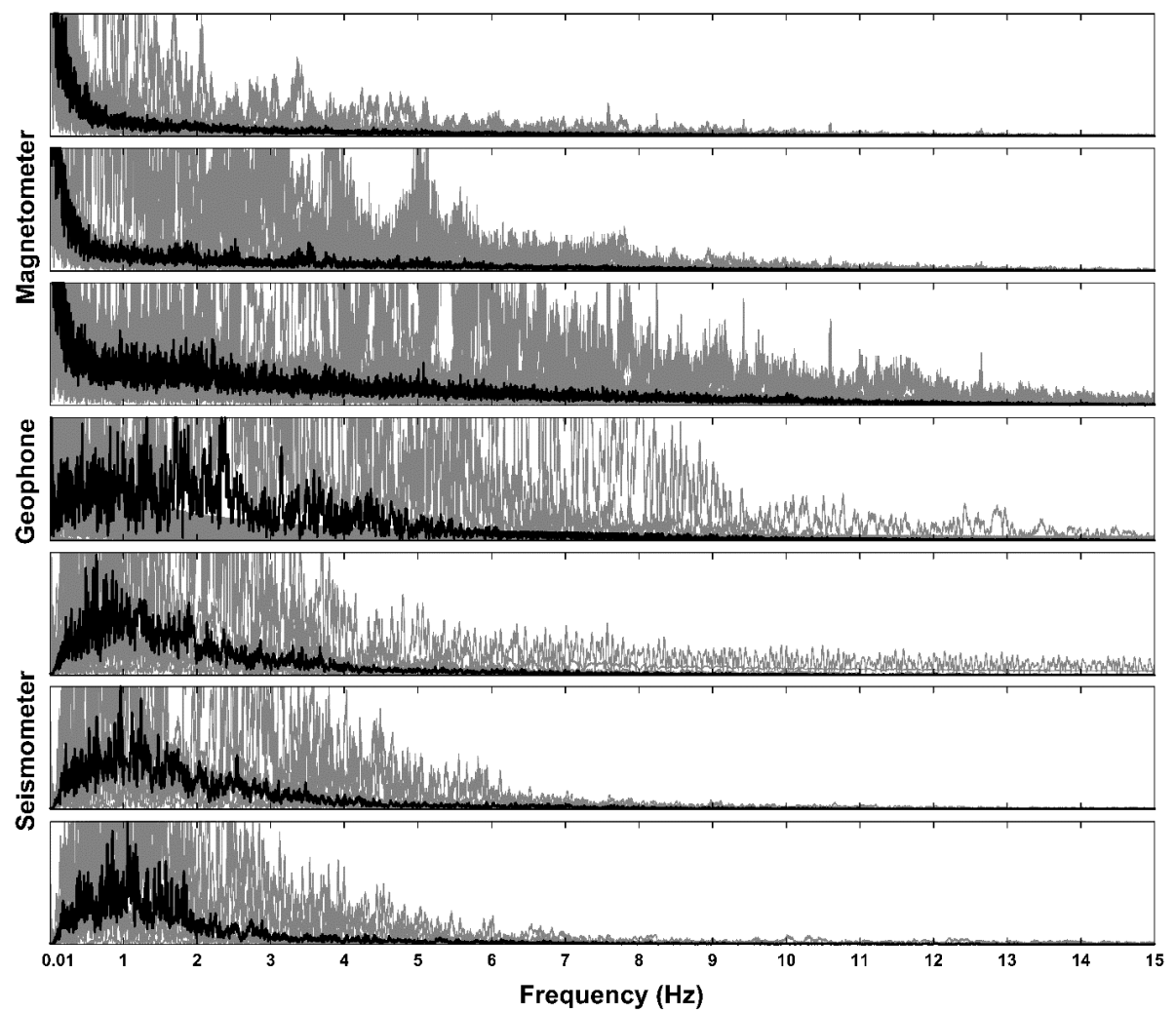

Fig. 4. Normalized power spectrum of the high sampling rate raw data of the magnetometers, the geophones, and seismometers. The spectrum has been normalized to the maximum amplitude. The gray curves are the individual spectra, while the heavy black curves are their associated median ones.

1.0 Hz. Likewise, Fig. 5 displays the power spectra of the low sampling data in the infrasound systems, micro-barometers, tiltmeters, and fluxgate magnetometers are generally inversely proportional to the frequency. The infrasound spectrum at $\mathrm{CCU}$ yields a prominent peak at $0.02 \mathrm{~Hz}$ and at DHU yields multiply peaks at the higher frequencies. To concern the overstepping data, spectra analyses of the tiltmeter data after $150 \mathrm{~s}$ was tested and results that no prominent different to those used whole time span. The tiltmeters spectrum have no significant peak expect for a peak range from $0.05-0.07 \mathrm{~Hz}$ at Y-component of NAH. Two filters are implemented to individual data set for further extract the fluctuations packet from noises, $0.5-2.5 \mathrm{~Hz}$ band-pass filter for QuakeFinder systems, seismometers, and fluxgate magnetometers, besides $0.25 \mathrm{~Hz}$ high-pass filter for infrasound systems, micro-barometers, and tiltmeters.

Figure 6 depicts filtered results at the QF sites shown in Fig. 2. At the nearest sites A and B, relatively short durations of about $30 \mathrm{~s}$ in the seismic waves recorded by the seismometers and geophones, while the durations of the associated co-seismic geomagnetic fluctuations are approximate $50 \mathrm{~s}$. Similarly, at the sites C, D, E, and G, the durations of geomagnetic fluctuations are longer than those of seismic waves. The filtering process results in that the co-seismic geomagnetic fluctuations can be observed at WT (site F), but not at SW (site H) and KD (site I). The 3 infrasound systems show vary different delay times that the infrasound fluctuations are nearly coincident with the P-wave at DHU (site A), overlap with the S-wave at CCU (site D), and lag the $\mathrm{S}$-wave by about $10-15 \mathrm{~s}$ at TTU (site G). Figure 7 illustrates the filtered data of the tiltmeters, micro-barometers, and the associated seismometers at LUG and NAH. The micro-barometer data are too noisy to be examined at LUG. The micro-barometer fluctuations lag the co-located S-wave by about $10-15 \mathrm{~s}$ at NAH. Similarly, the infrasound fluctuations also lag the co-located S-wave by about $10-15 \mathrm{~s}$ at TTU. The similarity suggests that the infrasound and the micro-barometer can sensitively record the atmospheric disturbances induced by S-waves. Although both seismometers and tiltmeters record the Earth's surface oscillations, the duration of tiltmeter oscillations is two times longer than that of the associated seismic waves.

\section{DISCUSSION}

Seismic waves attenuate during the propagation process (Chen 1998; Drouet et al. 2005), and co-seismic geomagnetic fluctuations also become weakened, when seismic waves 
traveling away from the epicenter (Liu et al. 2017). Liu et al. (2017) calculate the packet energy by summing up the square of wave amplitudes over the packet, and find that the energy of seismometers and geophones in exponentially decay to the distance away from the epicenter. To study seismic waves and their induced co-seismic geomagnetic fluctuations in detail, Fig. 8 displays $\dot{\mathrm{B}_{\mathrm{E}}}, \dot{\mathrm{B}_{\mathrm{Z}}}, \mathrm{V}_{\mathrm{E}}$, and $\mathrm{V}_{\mathrm{Z}}$ at $\mathrm{QF}$ sites versus corresponding distances away from the epicenter. The horizontal and vertical components of the co-seismic geomagnetic fluctuations quickly reduce as away from the epicenter, expect for the horizontal component at $\mathrm{CC}$ and the vertical component at SL, CC, and TY. Liu et al. (2017) study co-seismic geomagnetic fluctuations and suggest the underground structure at $\mathrm{CC}$ being rather complex. Figure 1 reveals that a huge positive anomaly appears around $\mathrm{CC}$, while the susceptibility model by Chen (2018) indicates that the underground structure at CC is mainly composed by high susceptibility rocks. Thus, the high susceptibility rocks might be responsible for the abnormal large geomagnetic fluctuations at CC. Although the vertical components being abnormal, the susceptibility at SL and TY are relatively low, which suggests that the abnormal large geomagnetic fluctuations might not be related to rock properties. On the other hand, it has been known the seismic intensity stands for the strong ground motion of peak ground acceleration (PGA) (Shearer 1999; Wu et al. 2003; Irwansyah et al. 2013). Figure 9 illustrates a PGA map produced by records of acceleration-type seismometers that the seismic intensity level decreases with the pattern of a concentric ring away from the epicenter, except two highlevel areas in central and western Taiwan, where SL and CC are located, respectively. It can be seen that with similar distances to the epicenter, the geomagnetic fluctuations at SL is of about 4 times larger than that at HS, while PGA 35 gal at SL and 8 gal at HS (Fig. 9), which is also approximately 4 times larger. Thus, the abnormal large geomagnetic fluctuations at SL shown in Fig. 8 result from a large level of the seismic intensity. Figures 1 and 9 further show that the most prominent anomaly of the co-seismic geomagnetic fluctuations appearing at $\mathrm{CC}$ is due to both high seismic intensity level and high susceptibility. Note that TY locates at neither high seismic intensity level nor high susceptibility but yields the large abnormal co-seismic geomagnetic fluctuations. To find possible explanation, we further examine hot springs island wide. It can be seen that TY locates at a dense area of 14 hot springs along the valley of the Laolung River, where is termed Paolai geothermal area (Chang and Lee 2001; Chang 2010; https://www.moeacgs.gov.tw). Therefore, motions of a large groundwater reservoir triggered by seismic waves are the responsible for the abnormal co-seismic geomagnetic fluctuations at TY.

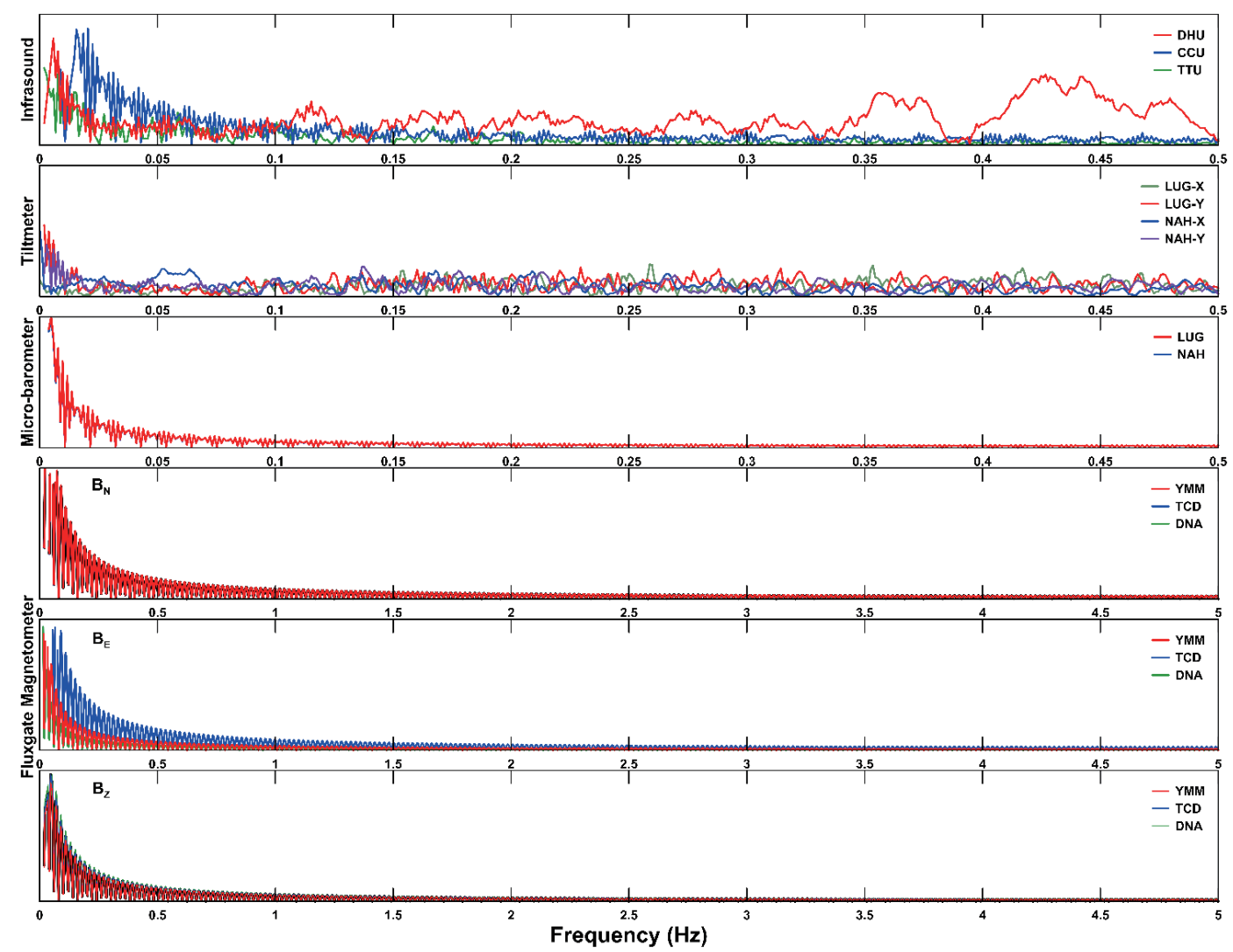

Fig. 5. Normalized power spectrum of the low sampling rate raw data of the infrasound systems, the tiltmeters, the micro-barometers, and the fluxgate magnetometers. The color curves are the individual spectra. 

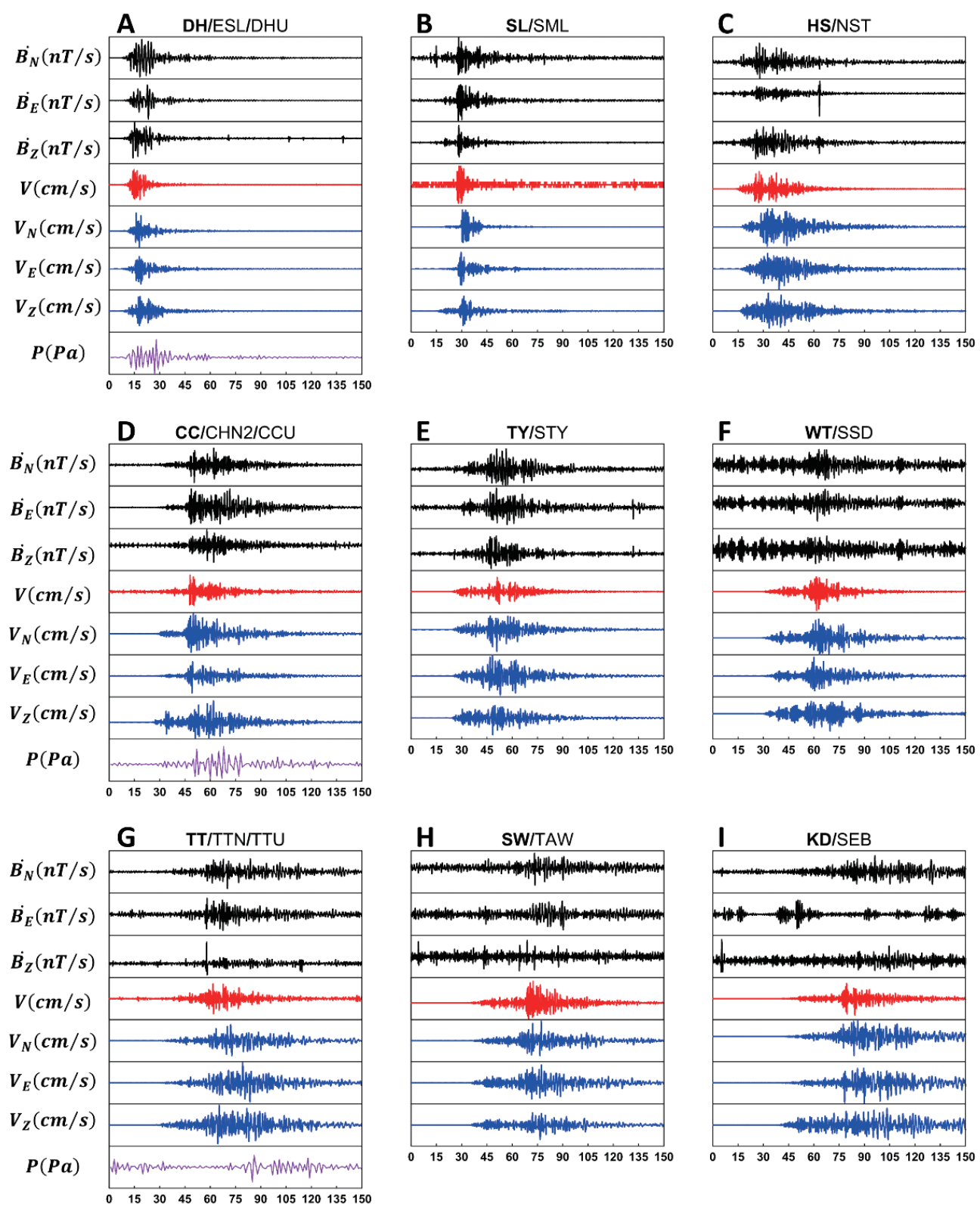

\section{Time after the earthquake (sec)}

Fig. 6. Filtered data of Fig. 2 with $0.5-2.5 \mathrm{~Hz}$ band-pass filter. The vertical axis range is in an arbitrary scale. 
(a) LUG (159 km) tiltmeter / micro-barometer \& WSF (166 km) seismometer

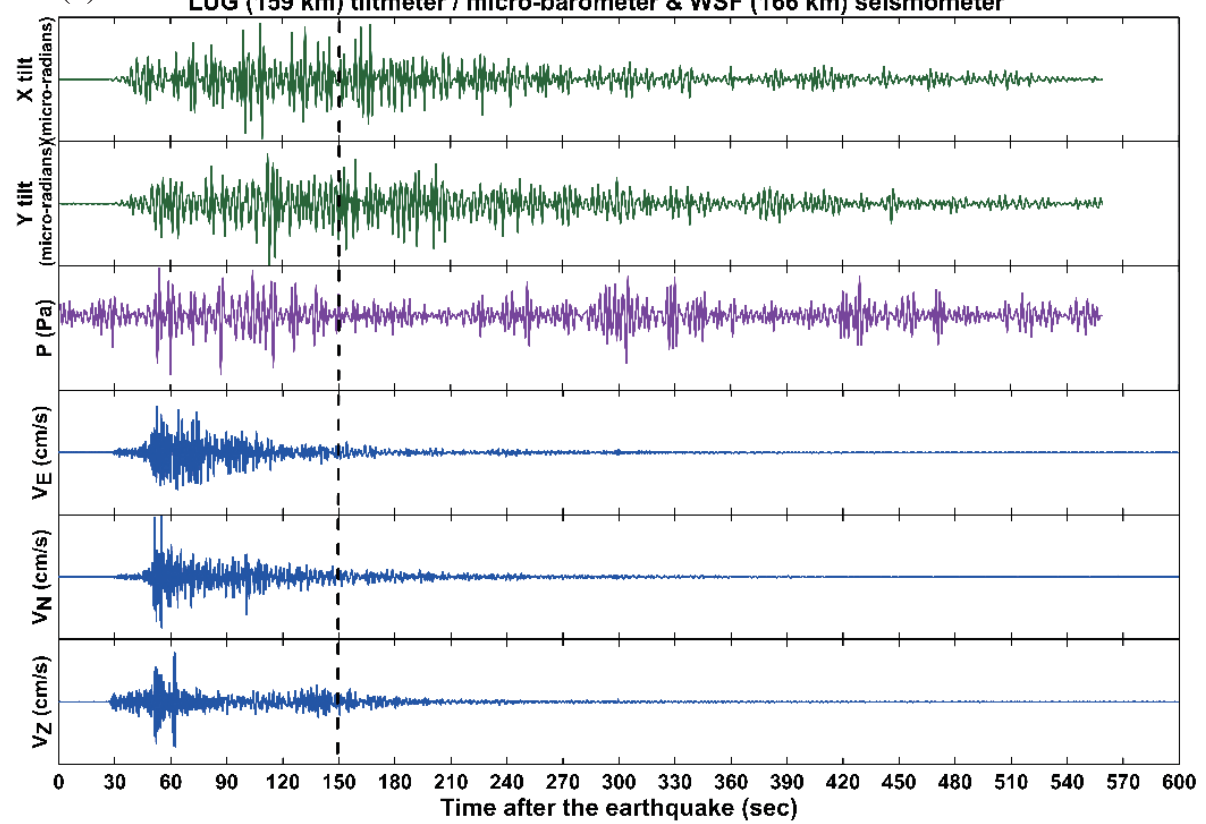

(b)

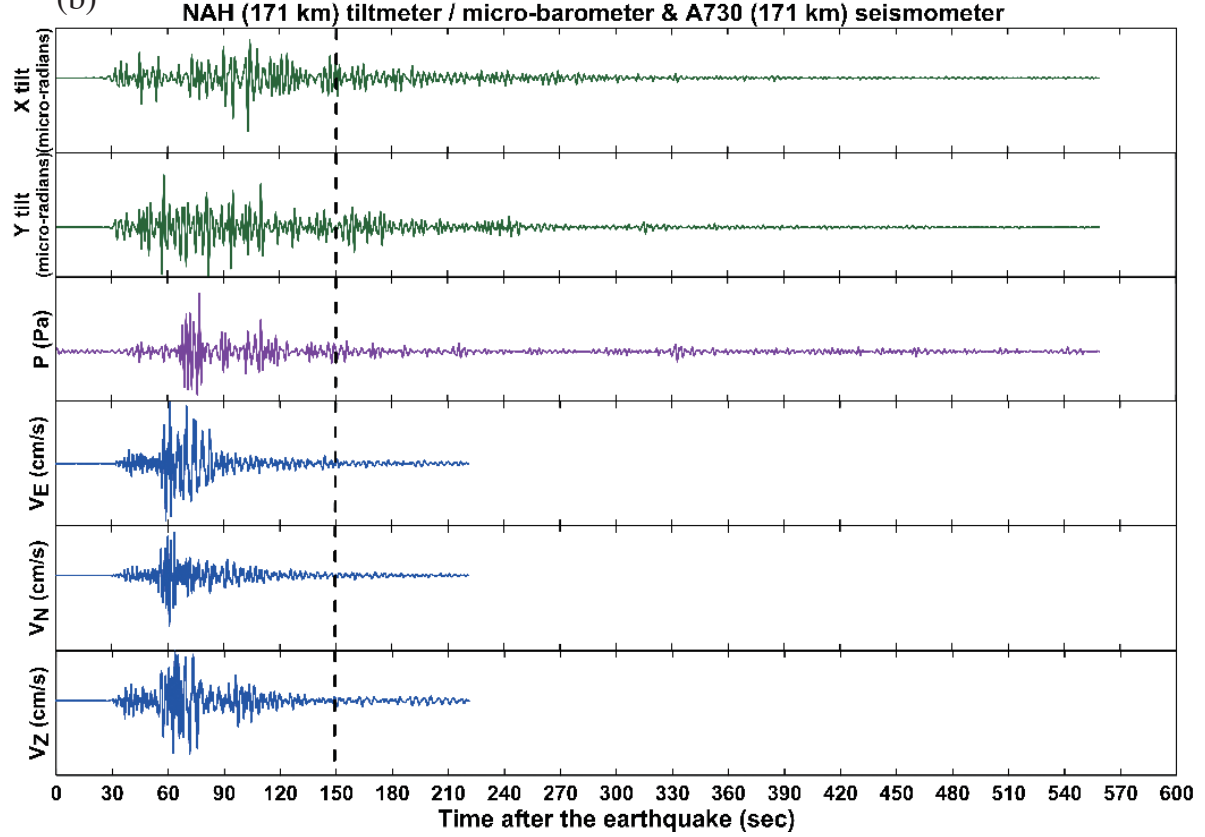

Fig. 7. Filtered data of Fig. 3 with $0.25 \mathrm{~Hz}$ high-pass filter. The vertical axis range is in an arbitrary scale. 
(a)

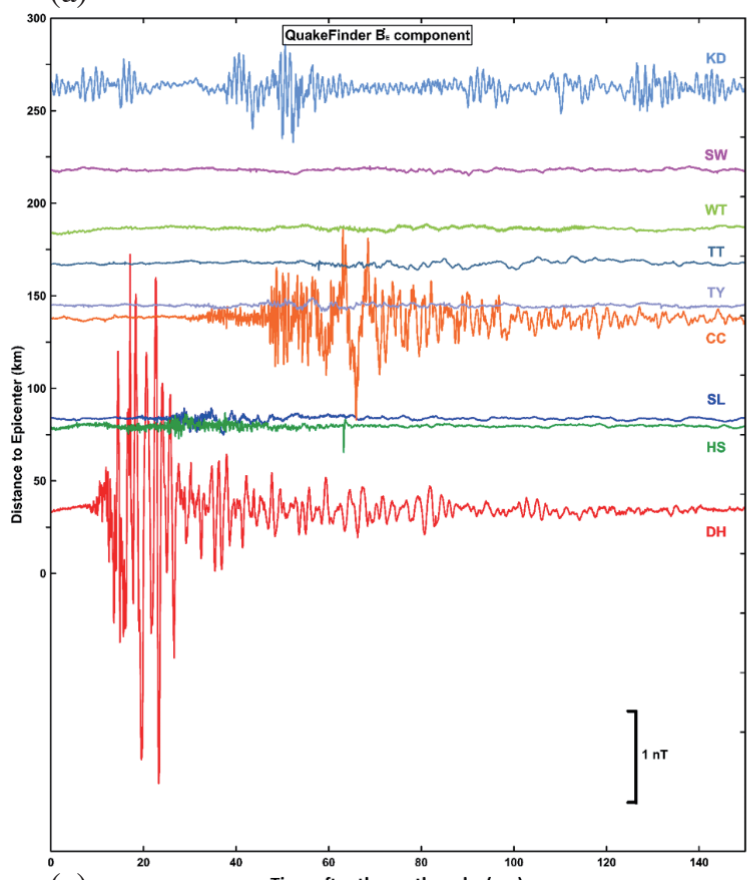

(c)

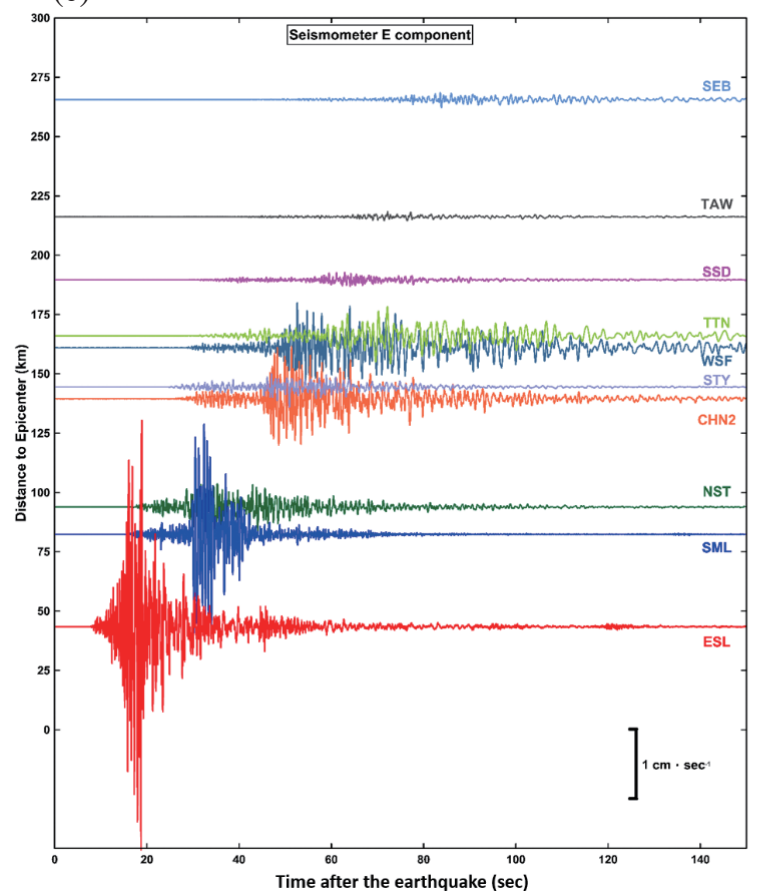

(b)

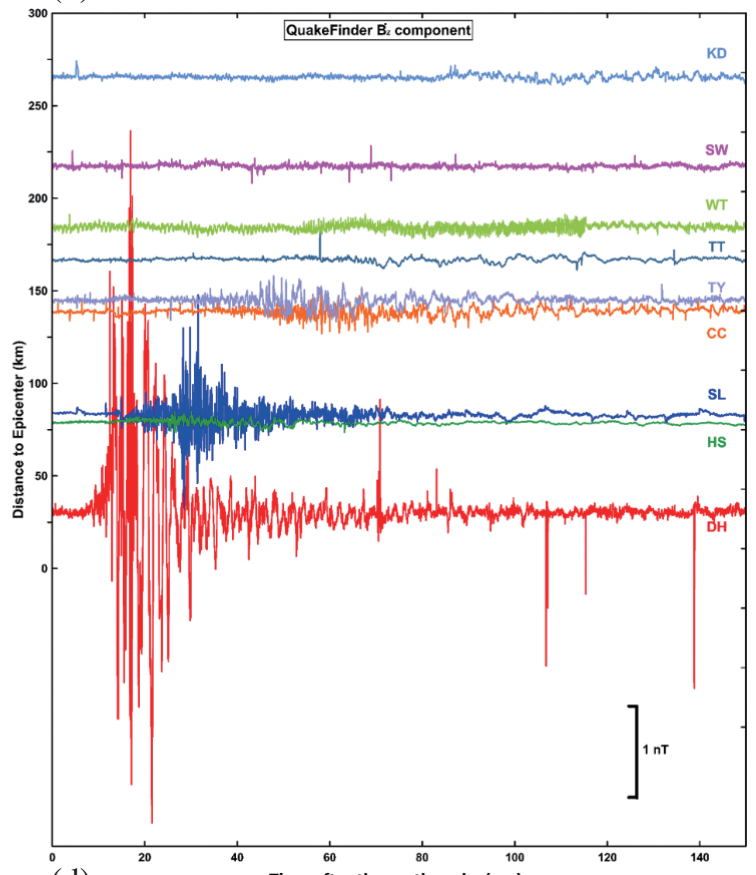

(d)

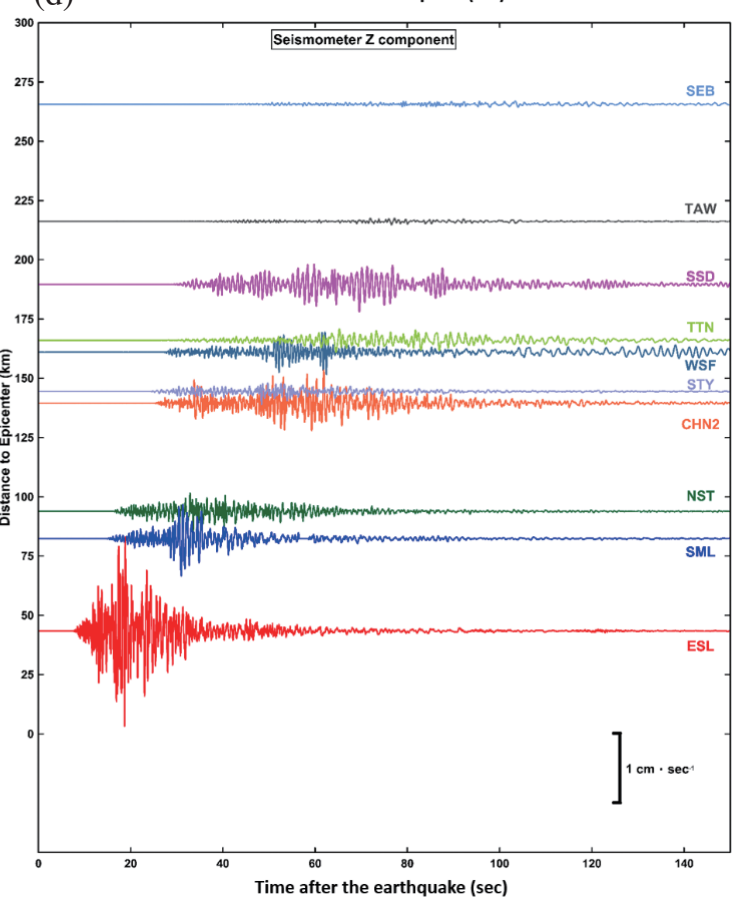

Fig. 8. The time series data of magnetic pulsations and seismic waves with the corresponding epicentral distance. (a) and (b) are the data of magnetic pulsations at $\mathrm{B}_{\mathrm{E}}$ and $\mathrm{B}_{\mathrm{Z}} \cdot(\mathrm{c})$ and (d) are the data in seismometers at $\mathrm{V}_{\mathrm{E}}$ and $\mathrm{V}_{\mathrm{Z}}$. 


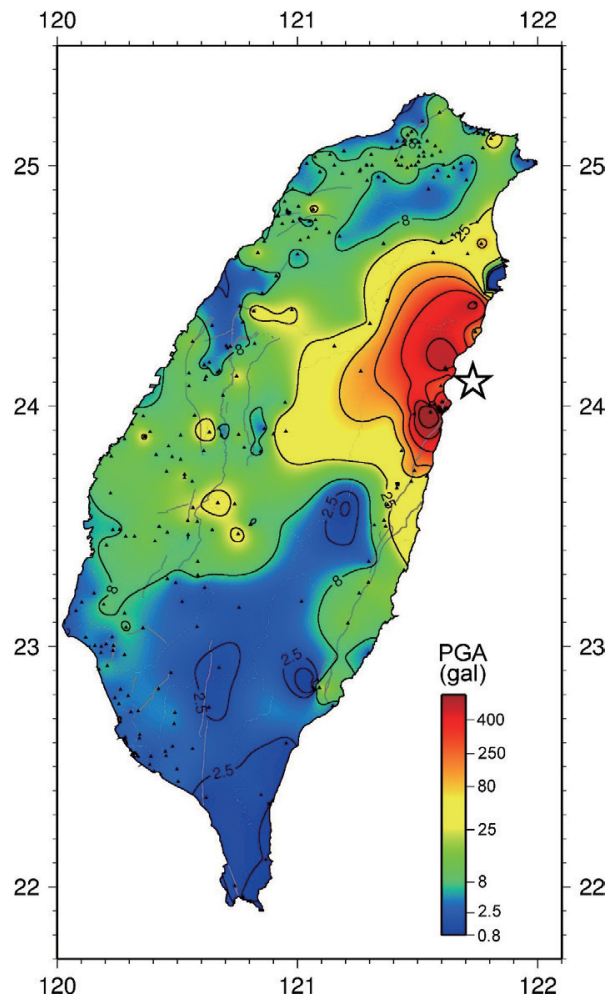

Fig. 9. The peak ground acceleration map. The open star indicated the epicenter and the black triangle are the seismometers in used (adapted from https://www.ncree.org/EarthquakeInfo/20180206/HualianEqTW_V7.2.pdf).

Gershenzon et al. (1993) found the earthquake magnitude dependence of co-seismic geomagnetic variations for piezomagnetic, electro-kinetic, and induction (dynamo) effects. Scientists study co-seismic magnetic pulsations and suggest that the low-frequency pulsations most likely result from motion of groundwater due to seismic waves (i.e., electro-kinetic effect) (Azeez et al. 2009; Ren et al. 2012, 2015, 2016; Gao and Hu 2010; Hu and Gao 2011; Gao et al. 2013a, b, 2016; Liu et al. 2017), while the high-frequency ones are due to shaking/tilting effects (i.e., magnetometer coil motion) (Widarto et al. 2009; Gao et al. 2014; Li et al. 2018).

Liu et al. (2017) use seismometers and geophones as high-frequency detectors for studying seismic waves, while in this study, we examine the seismic waves in both high- and low-frequency by seismometers, geophones, and tiltmeters. Tiltmeters can sensitively record the small shaking/tilting of Earth's oscillations, which generally is difficult to be detected by seismometers and geophones. At LUG and NAH, the durations of co-seismic tilting are two times longer than those of co-located seismometers, which shows that the Earth's surface has been still shaking and/or tilting after the seismic waves passing. Hence, the groundwater continues vibrating and in turn shaking the Earth's surface, which is further detected by the magnetometers but not the seismometers. Note at sites A, B, C, D, E, and $\mathrm{G}$ that the durations of co-seismic geomagnetic fluctuations are longer than those of seismic waves recorded by the geophones. This suggests that the coseismic geomagnetic fluctuations could be contributed by both the Earth's surface motion on the magnetometers and the induction by the groundwater motion. Figure 10 reveals the 3-components fluxgate magnetometer data after a 0.5 $2.5 \mathrm{~Hz}$ band-pass filter being applied. At YMM and TCD, due to similar epicentral distances, co-seismic geomagnetic fluctuations in the $B_{x}$ and $B_{y}$ components of the 2 stations are rather similar. The durations of the co-seismic geomagnetic fluctuations are about $50 \mathrm{~s}$, while those of the associated colocated seismic waves are less than $30 \mathrm{~s}$. Once again, this indicates that both surface motion and groundwater motion contribute the co-seismic geomagnetic fluctuations.

Scientists report that seismic waves can perturb the near Earth's atmosphere, activate disturbances within, which further propagate upward into the ionosphere, modulate the E-region conductivity, and in turn induce seismo-magnetic pulsations. Due to the propagation of the atmospheric disturbances, seismic waves tend to lead their co-located coseismic geomagnetic pulsations by about $200 \mathrm{~s}$ (Iyemori et al. 2005; Hao et al. 2013; Yen et al. 2015; Liu et al. 2016a). By contrast, Fig. 6 shows there is almost no time lag between geomagnetic fluctuations and seismic waves. Therefore, the co-seismic geomagnetic fluctuations in this study are unlikely related to the ionospheric conductivity but directly produced by both surface motion and groundwater motion. 
(a)

YMM 3-Componets magnetometer
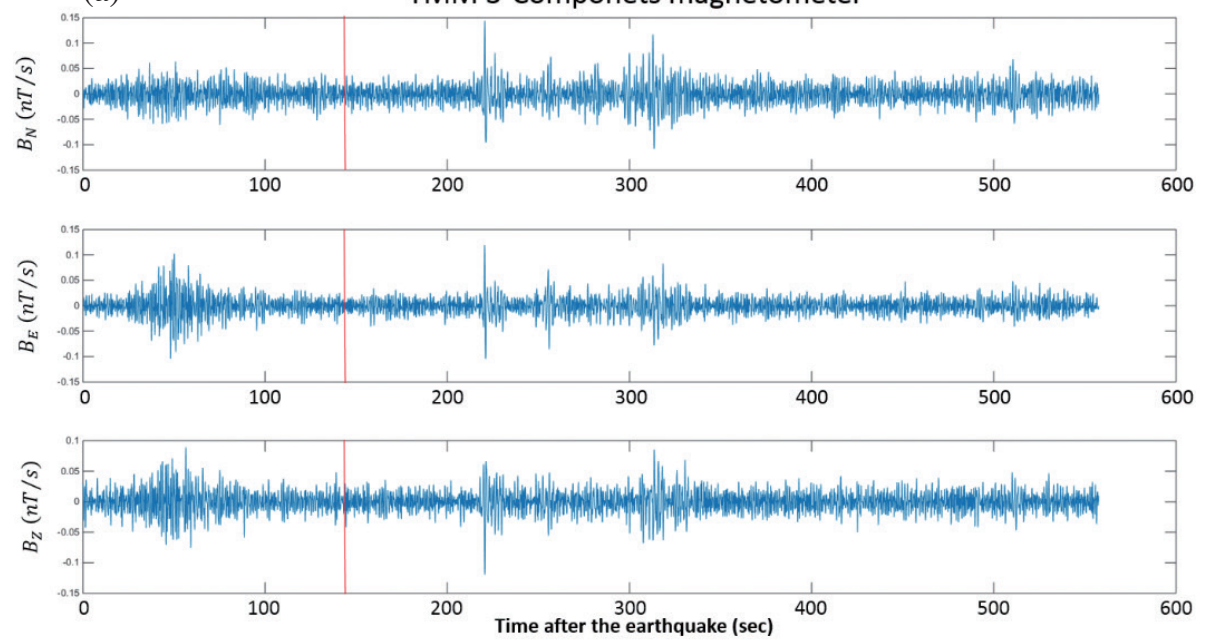

(b)

TCD 3-Componets magnetometer
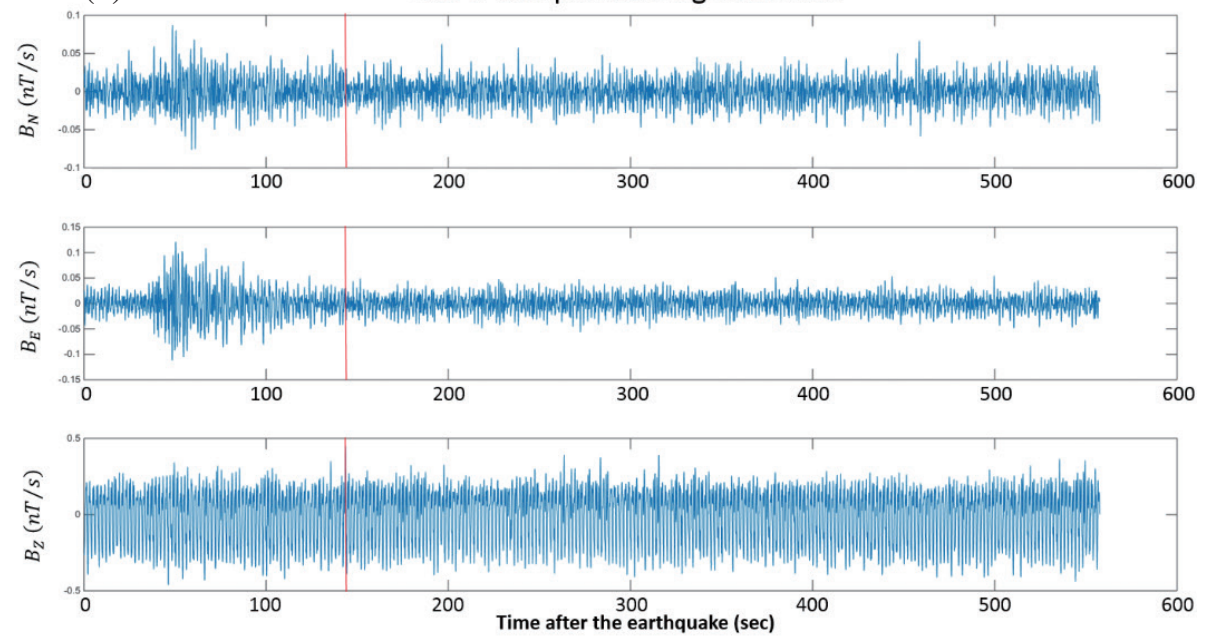

(c)

DNA 3-Componets magnetometer
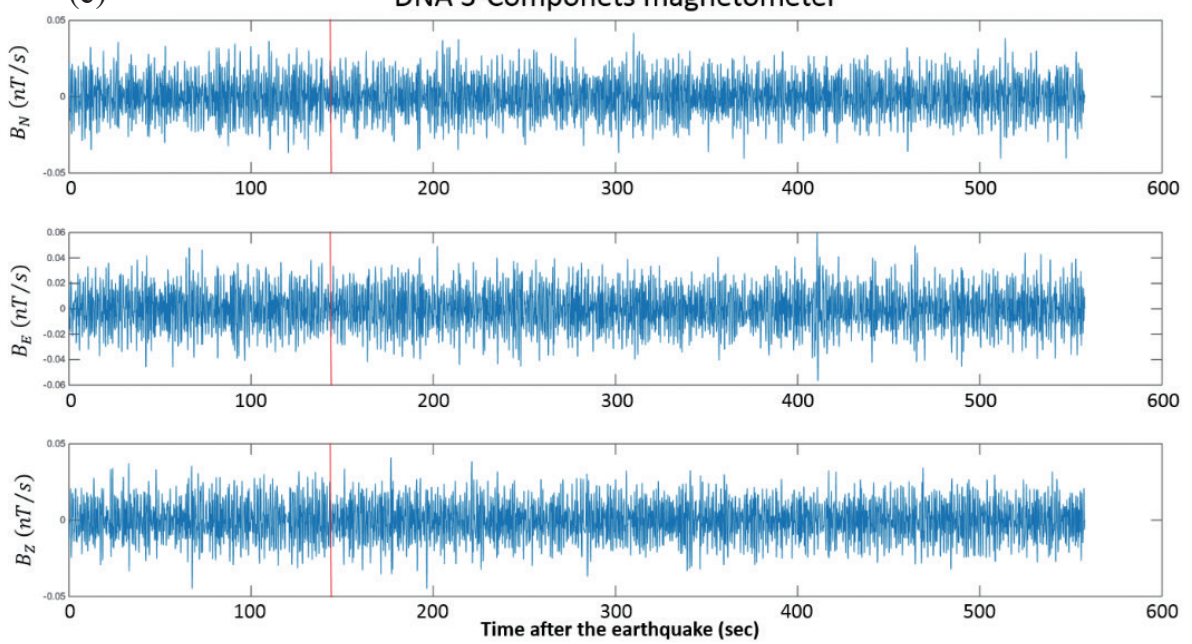

Fig. 10. The filtered data in fluxgate magnetometers. The red line indicate the time window (150 s) in Fig. 2. 
Figures 6 and 7 display the time lags of the co-seismic infrasound fluctuations and micro-barometer fluctuations to the co-located seismic waves, respectively. Due to nearby the epicenter (the distance of $29.66 \mathrm{~km}$ ), at DHU the time lag between the infrasound fluctuation and simultaneous Pwave/S-wave is a very small value (i.e., their starting times are nearly identical). At CCU, where is about $141.52 \mathrm{~km}$ away from the epicenter, the P-wave arrives first and is followed by the S-wave, and then the Rayleigh wave. The infrasound fluctuations and the S-wave almost simultaneously appear, since the seismogram shows that the S-wave amplitude is the largest among the 3 waves. At TTU (the epicentral distance of $166.97 \mathrm{~km}$ ), the P-wave and S-wave are significantly damped, and therefore, fluctuations in the infrasonic wave and the Rayleigh wave concurrently appear. Similarly, at NAH (the epicentral distance of $171.67 \mathrm{~km}$ ), the micro-barometer wave and the Rayleigh wave simultaneously fluctuate. The above results show that at a location far away from the epicenter, the amplitude of surface waves is greater than that of bodies waves, which agrees with pervious observations (Artru et al. 2004; Guglielmi et al. 2004; Honkura et al. 2004; Yamazaki 2012).

Iyemori et al. (1996) suggests that high resolution observations are necessary for co-seismic geomagnetic studies. Although the proton total magnetometer with the $1-\mathrm{Hz}$ sam- pling rate is not very suitable to detect co-seismic geomagnetic fluctuations, Fig. 11 reveals some interesting features that the geomagnetic total field highly and constantly fluctuate at $\mathrm{HL}$, while 3 pulse-like decreases appear at $\mathrm{NC}$ and $\mathrm{YH}$ 20 - $60 \mathrm{~s}$ after the earthquake. The highly fluctuations in the geomagnetic total field often appear at HL, where is nearby the railroad, which result in the co-seismic feature being difficult studied. The magnified plot of Fig. 11b shows that the 3 pulse-like decreases of about $10 \mathrm{nT}$ at $\mathrm{NC}$ and $4 \mathrm{nT}$ at $\mathrm{YH}$ in comparing the associated background variations during $0-120 \mathrm{~s}$ after the earthquake (the diurnal variation) of $4 \mathrm{nT}(25 \mathrm{nT})$ and $5 \mathrm{nT}(33 \mathrm{nT})$, respectively. These suggest that the pulse-like decreases are related to the earthquake. $\mathrm{NC}$ and $\mathrm{YH}$ roughly have similar distances to the epicenter, and however the co-seismic fluctuations at $\mathrm{NC}$ are about three times larger than those at YH. Figure 1 shows that geomagnetic anomaly at $\mathrm{NC}$ are greater than that at $\mathrm{YH}$, which suggest that the high susceptibility results in the strong coseismic induction geomagnetic field (Chen 2018).

\section{SUMMARY AND CONCLUSION}

In this study, we report the co-seismic signatures in various instruments of the induction magnetometers, geophones, infrasound systems, tiltmeters, micro-barometers,

(a)

Total Geomagnetic Field

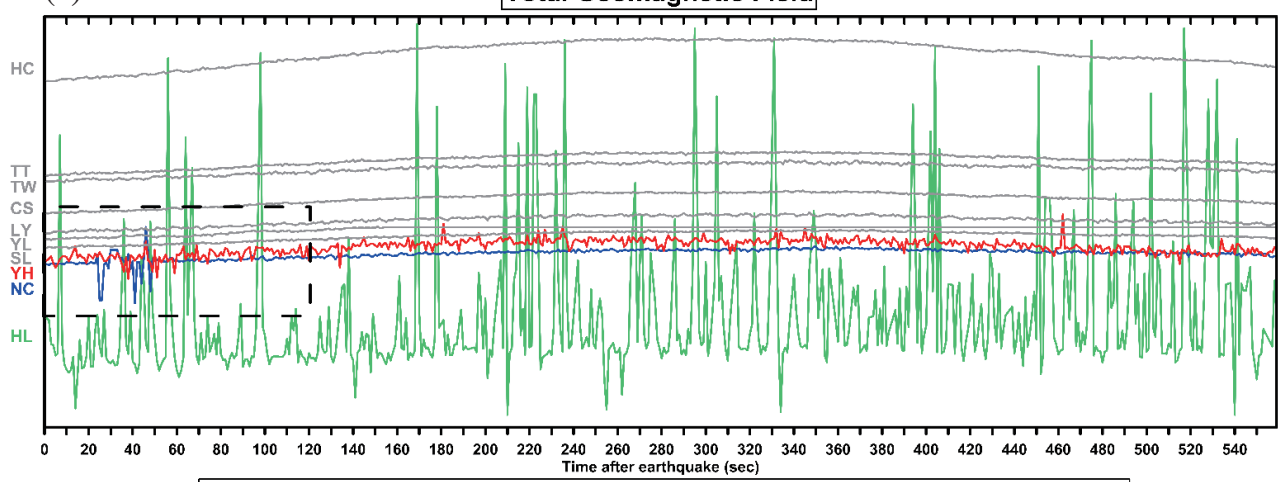

(b)

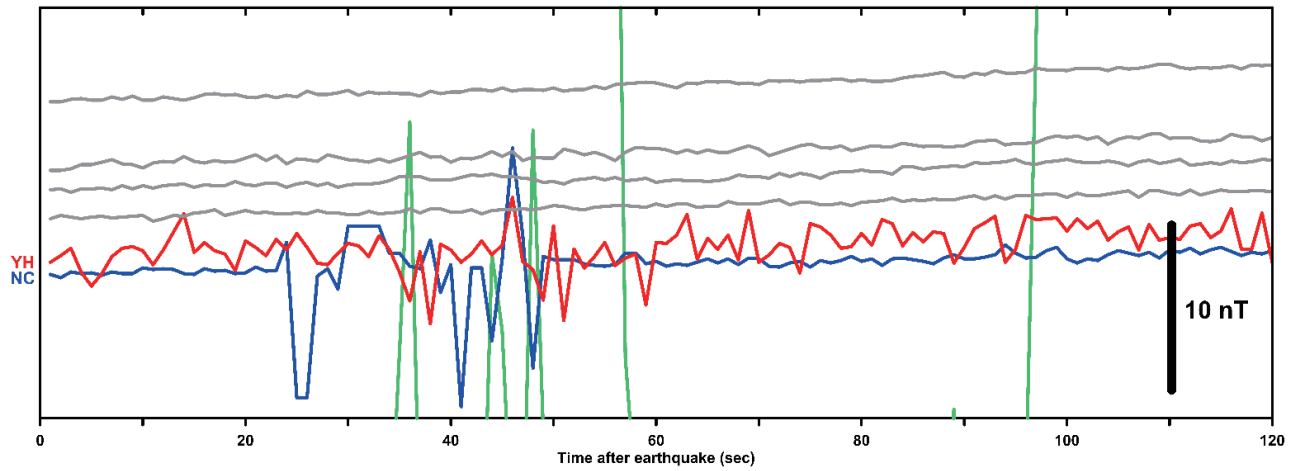

Fig. 11. The proton total magnetometer data after the earthquake. (a) Raw data in the proton total magnetometer network within the earthquake event. There have 10 stations were well operating but HL station had some strong influences. (b) The magnified plot of dash square in (a). There are 3 pulse-like decreases of about $10 \mathrm{nT}$ at $\mathrm{NC}$ and $4 \mathrm{nT}$ at $\mathrm{YH}$. 
and fluxgate magnetometers. This is for the first time that micro-barometers and tiltmeters are employed to detect coseismic fluctuations. The results show that the co-seismic geomagnetic fluctuations are functions of the susceptibility and/or PGA. Due to the greatest susceptibility in Taiwan and a relatively large PGA, CC yields the $2^{\text {nd }}$ most prominent co-seismic geomagnetic fluctuations. The long lasting tilting/shaking recorded by the tiltmeters indicates that both the groundwater motion and its vibrated Earth's surface motion in the low-frequency band induce the co-seismic fluctuations via the electro-kinetic effect. The study of the co-seismic infrasound and micro-barometer fluctuations response to the P-wave, S-wave and Rayleigh wave at various distances confirm that the Rayleigh wave can efficiently activate prominent co-seismic signatures even at far away from the epicenter.

Acknowledgements This work was financially supported by the Center for Astronautical Physics and Engineering (CAPE) from the Featured Area Research Center program within the framework of Higher Education Sprout Project by the Ministry of Education (MOE) in Taiwan. This study is supported by the Taiwan Ministry of Science and Technology (MOST) grant MOST 106-2628-M-008-002 and the ISSI-Bern International Team of "Ionospheric Space Weather Studied by RO and Ground-based GNSS TEC Observations" [the team leader Liu, J. Y. Tiger (TW)]. The authors thank to the data owner which seismic data used in this paper was provided from CWB (http://gdms.cwb.gov. tw/index.php) and NCREE. The total magnetic field data was also provided from CWB.

\section{REFERENCES}

Artru, J., T. Farges, and P. Lognonné, 2004: Acoustic waves generated from seismic surface waves: Propagation properties determined from Doppler sounding observations and normal-mode modelling. Geophys. J.Int., 158, 1067-1077, doi: 10.1111/j.1365-246X.2004.02377.x. [Link]

Azeez, K. K. A., C. Manoj, K. Veeraswamy, and T. Harinarayana, 2009: Co-seismic EM signals in magnetotelluric measurement $-\mathrm{A}$ case study during Bhuj earthquake (26th January 2001), India. Earth Planets Space, 61, 973-981, doi: 10.1186/BF03352947. [Link]

Breiner, S., 1964: Piezomagnetic effect at the time of local earthquakes. Nature, 202, 790-791, doi: 10.1038/202790a0. [Link]

Chang, B. T., 2010: Taiwan hot spring resource and industry. Taiwan Mineral Industry, 62, 68-76, doi: 10.30014/ TMI.201012.0008. (in Chinese) [Link]

Chang, B. T. and C. S. Lee, 2001: Geology of geothermal at Paolai area. Geology, 21, 1-18. (in Chinese)

Chen, C.-H., S. Wen, J.-Y. Liu, T.-K. Yeh, C.-H. Wang,
H.-Y. Yen, K. Hattori, and C.-R. Lin, 2011: Seismomagnetic Signal Comparison using the Morlet Wavelet Method. Disaster Adv., 4, 53-60.

Chen, C.-H., C.-H. Wang, S. Wen, T.-K. Yeh, C.-H. Lin, J.-Y. Liu, H.-Y. Yen, C. Lin, R.-J. Rau, and T.-W. Lin, 2013: Anomalous frequency characteristics of groundwater level before major earthquakes in Taiwan. $H y$ drol. Earth Syst. Sci., 17, 1693-1703, doi: 10.5194/ hess-17-1693-2013. [Link]

Chen, C.-H., C.-H. Wang, L.-C. Lin, H.-H. Hsieh, H.-Y. Yen, and M.-H. Shih, 2014: Typhoon-induced magnetic disturbances: Cases in the Western Pacific. Terr. Atmos. Ocean. Sci., 25, 647-653, doi: 10.3319/ TAO.2014.05.08.01(AA). [Link]

Chen, C. R., 2018: The study of the subsurface magnetic structure in Taiwan. Ph.D. Thesis, National Central University, Taoyuan City, Taiwan, $150 \mathrm{pp}$.

Chen, K.-J., 1998: S-Wave attenuation structure in the Taiwan area and its correlation to seismicity. Terr. Atmos. Ocean. Sci., 9, 97-118, doi: 10.3319/ TAO.1998.9.1.97(T). [Link]

Davies, K., 1990: Ionospheric Radio. IEE electromagnetic wave series, Vol. 31, Peter Peregrinus Ltd., London, $580 \mathrm{pp}$.

Drouet, S., A. Souriau, and F. Cotton, 2005: Attenuation, seismic moments, and site effects for weak-motion events: Application to the Pyrenees. Bull. Seismol. Soc. Am., 95, 1731-1748, doi: 10.1785/0120040105. [Link]

Eleman, F., 1965: The response of magnetic instruments to earthquake waves. J. Geomagn. Geoelectr., 18, 43-72, doi: 10.5636/jgg.18.43. [Link]

Gao, Y. and H. Hu, 2010: Seismoelectromagnetic waves radiated by a double couple source in a saturated porous medium. Geophys. J. Int., 181, 873-896, doi: 10.1111/j.1365-246X.2010.04526.x. [Link]

Gao, Y., X. Chen, H. Hu, and J. Zhang, 2013a: Early electromagnetic waves from earthquake rupturing: I. Theoretical formulations. Geophys. J. Int., 192, 1288-1307, doi: 10.1093/gji/ggs096. [Link]

Gao, Y., X. Chen, H. Hu, and J. Zhang, 2013b: Early electromagnetic waves from earthquake rupturing: II. Validation and numerical experiments. Geophys. J. Int., 192, 1308-1323, doi: 10.1093/gji/ggs097. [Link]

Gao, Y., X. Chen, H. Hu, J. Wen, J. Tang, and G. Fang, 2014: Induced electromagnetic field by seismic waves in Earth's magnetic field. J. Geophys. Res., 119, 56515685, doi: 10.1002/2014JB010962. [Link]

Gao, Y., J. M. Harris, J. Wen, Y. Huang, C. Twardzik, X. Chen, and H. Hu, 2016: Modeling of the coseismic electromagnetic fields observed during the $2004 M_{w}$ 6.0 Parkfield earthquake. Geophys. Res. Lett., 43, 620627, doi: 10.1002/2015GL067183. [Link]

Gershenzon, N. I., M. B. Gokhberg, and S. L. Yunga, 1993: On the electromagnetic field of an earthquake 
focus. Phys. Earth Planet. Inter., 77, 13-19, doi: 10.1016/0031-9201(93)90030-D. [Link]

Guglielmi, A. V., A. S. Potapov, and B. Tsegmed, 2004: On the excitation of magnetic signals by Love waves. Ann. Geophys., 47, 171-177, doi: 10.4401/ag-3269. [Link]

Han, P., K. Hattori, M. Hirokawa, J. Zhuang, C. H. Chen, F. Febriani, H. Yamaguchi, C. Yoshino, J. Y. Liu, and S. Yoshida, 2014: Statistical analysis of ULF seismomagnetic phenomena at Kakioka, Japan, during 2001-2010. J. Geophys. Res., 119, 4998-5011, doi: 10.1002/2014JA019789. [Link]

Hao, Y. Q., Z. Xiao, and D. H. Zhang, 2013: Teleseismic magnetic effects (TMDs) of 2011 Tohoku earthquake. J. Geophys. Res., 118, 3914-3923, doi: 10.1002/ jgra.50326. [Link]

Honkura, Y., M. Matsushima, N. Oshiman, M. K. Tunçer, Ş. Bariş, A. Ito, Y. Iio, and A. M. Işikara, 2002: Small electric and magnetic signals observed before the arrival of seismic wave. Earth Planets Space, 54, e9-e12, doi: 10.1186/BF03352449. [Link]

Honkura, Y., H. Satoh, and N. Ujihara, 2004: Seismic dynamo effects associated with the M7.1 earthquake of 26 May 2003 off Miyagi Prefecture and the M6.4 earthquake of 26 July 2003 in northern Miyagi Prefecture, NE Japan. Earth Planets Space, 56, 109-114, doi: 10.1186/BF03353395. [Link]

$\mathrm{Hu}, \mathrm{H}$. and Y. Gao, 2011: Electromagnetic field generated by a finite fault due to electrokinetic effect. J. Geophys. Res., 116, B08302, doi: 10.1029/2010JB007958. [Link]

Huang, H.-H., Y.-M. Wu, X. Song, C.-H. Chang, S.-J. Lee, T.-M. Chang, and H.-H. Hsieh, 2014: Joint Vp and Vs tomography of Taiwan: Implications for subductioncollision orogeny. Earth Planet. Sci. Lett., 392, 177191, doi: 10.1016/j.eps1.2014.02.026. [Link]

Irwansyah, E., E. Winarko, Z. E. Rasjid, and R. D. Bekti, 2013: Earthquake hazard zonation using peak ground acceleration (PGA) approach. J. Phys. Conf., 423, 012067, doi: 10.1088/1742-6596/423/1/012067. [Link]

Iyemori, T., T. Kamei, Y. Tanaka, M. Takeda, T. Hashimoto, T. Araki, T. Okamoto, K. Watanabe, N. Sumitomo, and N. Oshiman, 1996: Co-Seismic geomagnetic variations observed at the 1995 Hyogoken-Nanbu Earthquake. J. Geomagn. Geoelectr., 48, 1059-1070, doi: 10.5636/jgg.48.1059. [Link]

Iyemori, T., M. Nose, D. Han, Y. Gao, M. Hashizume, N. Choosakul, H. Shinagawa, Y. Tanaka, M. Utsugi, A. Saito, H. McCreadie, Y. Odagi, and F. Yang, 2005: Geomagnetic pulsations caused by the Sumatra earthquake on December 26, 2004. Geophys. Res. Lett., 32, L20807, doi: 10.1029/2005GL024083. [Link]

Kuo-Chen, H., F. T. Wu, and S. W. Roecker, 2012: Threedimensional P velocity structures of the lithosphere beneath Taiwan from the analysis of TAIGER and related seismic data sets. J. Geophys. Res., 117, B06306, doi:

\subsection{9/2011JB009108. [Link]}

Li, J., Y. Xu, L. Zhu, Y. Liu, D. Li, and R. Huang, 2018: Rotation-induced magnetic field in a coil magnetometer generated by seismic waves. Geophys. J. Int., 212, 743-759, doi: 10.1093/gji/ggx423. [Link]

Liu, J.-Y., Y. N. Huang, and F. T. Berkey, 1993: The phase relationship between ULF geomagnetic pulsations and HF Doppler frequency shift oscillations on March 24, 1991. J. Geomagn. Geoelectr., 45, 109-114, doi: 10.5636/jgg.45.109. [Link]

Liu, J.-Y., Y. B. Tsai, S. W. Chen, C. P. Lee, Y. C. Chen, H. Y. Yen, W. Y. Chang, and C. Liu, 2006: Giant ionospheric disturbances excited by the M9.3 Sumatra earthquake of 26 December 2004. Geophys. Res. Lett., 33, L02103, doi: 10.1029/2005GL023963. [Link]

Liu, J.-Y., H. F. Tsai, C. H. Lin, M. Kamogawa, Y. I. Chen, C. H. Lin, B. S. Huang, S. B. Yu, and Y. H. Yeh, 2010: Coseismic ionospheric disturbances triggered by the Chi-Chi earthquake. J. Geophys. Res., 115, A08303, doi: 10.1029/2009JA014943. [Link]

Liu, J.-Y., C. H. Chen, Y. Y. Sun, C. H. Chen, H. F. Tsai, H. Y. Yen, J. Chum, J. Lastovicka, Q. S. Yang, W. S. Chen, and S. Wen, 2016a: The vertical propagation of disturbances triggered by seismic waves of the 11 March 2011 M 9.0 Tohoku Earthquake over Taiwan. Geophys. Res. Lett., 43, 1759-1765, doi: 10.1002/2015GL067487. [Link]

Liu, J.-Y., Y.-B. Tsai, C.-H. Chen, Y.-I. Chen, and H.-Y. Yen, 2016b: Integrated Search for Taiwan Earthquake Precursors (iSTEP). IEEJ Trans. Fund. Materials, 136, 214-220, doi: 10.1541/ieejfms.136.214. [Link]

Liu, J.-Y., L. C.-W. Chang, C.-K. Chao, M.-Q. Chen, Y.H. Chu, L.-N. Hau, C.-M. Huang, C.-L. Kuo, L.-C. Lee, L.-H. Lyu, C.-H. Lin, C.-J. Pan, J.-H. Shue, C.-L. Su, L.-C. Tsai, Y.-H. Yang, C.-H. Lin, R.-R. Hsu, and H.-T. Su, 2016c: The fast development of solar terrestrial sciences in Taiwan. Geosci. Lett., 3, 1-12, doi: 10.1186/s40562-016-0049-0. [Link]

Liu, J.-Y., C.-H. Chen, T.-Y. Wu, H.-C. Chen, K. Hattori, I.-C. Yang, T. Bleier, K. Kappler, Y. Xia, W. Chen, and Z. Liu, 2017: Co-seismic signatures in magnetometer, geophone, and infrasound data during the Meinong Earthquake. Terr. Atmos. Ocean. Sci., 28, 683692, doi: 10.3319/TAO.2017.03.05.01. [Link]

Mutschlecner, J. P. and R. W. Whitaker, 2005: Infrasound from earthquakes. J. Geophys. Res., 110, D01108, doi: 10.1029/2004JD005067. [Link]

Ren, H., X. Chen, and Q. Huang, 2012: Numerical simulation of coseismic electromagnetic fields associated with seismic waves due to finite faulting in porous media. Geophys. J. Int., 188, 925-944, doi: 10.1111/j.1365246X.2011.05309.x. [Link]

Ren, H., J. Wen, Q. Huang, and X. Chen, 2015: Electrokinetic effect combined with surface-charge assumption: 
A possible generation mechanism of coseismic EM signals. Geophys. J. Int., 200, 837-850, doi: 10.1093/ gji/ggu435. [Link]

Ren, H., Q. Huang, and X. Chen, 2016: Numerical simulation of seismo-electromagnetic fields associated with a fault in a porous medium. Geophys. J. Int., 206, 205220, doi: 10.1093/gji/ggw144. [Link]

Shearer, P. M., 1999: Introduction to Seismology, Cambridge University Press, 260 pp.

Widarto, D. S., T. Mogi, Y. Tanaka, T. Nagao, K. Hattori, and S. Uyeda, 2009: Co-seismic geoelectrical potential changes associated with the June 4, 2000's earthquake (Mw7.9) in Bengkulu, Indonesia. Phys. Chem. Earth, 34, 373-379, doi: 10.1016/j.pce.2008.09.009. [Link]

Wu, Y.-M., T. Teng, T.-C. Shin, and N.-C. Hsiao, 2003: Relationship between peak ground acceleration, peak ground velocity, and intensity in Taiwan. Bull. Seismol. Soc. Am., 93, 386-396, doi: 10.1785/0120020097. [Link]

Xia, Y., J.-Y.T.Liu, X. Cui, J.Li, W.Chen, and C. Liu, 2011: Abnormal infrasound signals before $92 M \geq 7.0$ world- wide earthquakes during 2002-2008. J. Asian Earth Sci., 41, 434-441, doi: 10.1016/j.jseaes.2010.04.015. [Link]

Yamazaki, K., 2012: Estimation of temporal variations in the magnetic field arising from the motional induction that accompanies seismic waves at a large distance from the epicentre. Geophys. J. Int., 190, 1393-1403, doi: 10.1111/j.1365-246X.2012.05586.x. [Link]

Yen, H.-Y., C.-H. Chen, H.-H. Hsieh, C.-R. Lin, Y.-H. Yeh, Y.-B. Tsai, J.-Y. Liu, G.-K. Yu, and Y .-R. Chen, 2009: Magnetic Survey of Taiwan and Its Preliminary Interpretations. Terr. Atmos. Ocean. Sci., 20, 309-314, doi: 10.3319/TAO.2008.04.08.01(T). [Link]

Yen, H.-Y., C.-R. Chen, Y.-T. Lo, T.-C. Shin, and Q. Li, 2015: Seismo-geomagnetic pulsations triggered by Rayleigh waves of the 11 March 2011 M 9.0 Tohokuoki earthquake. Terr. Atmos. Ocean. Sci., 26, 95-101, doi: 10.3319/TAO.2014.10.09.01(T). [Link]

Yeh, Y.-H., Y.-B. Tsai, and T.-L. Teng, 1981: Investigations of geomagnetic total intensity in Taiwan from 1979 to 1981. Bull. Inst. Earth Sci. Acad. Sin., 1, 157-187. 